\title{
A adolescência como construção social: estudo sobre livros destinados a pais e educadores
}

\author{
Adolescência como uma construção social
}

\author{
Ana Mercês Bahia Bock
}

\section{Resumo}

A adolescência tem sido tema de interesse na sociedade e, conseqüentemente, a Psicologia tem dedicado a ela espaço importante, tanto no campo da Psicologia do Desenvolvimento quanto nas áreas de Psicologia da Educação e Psicologia Social. Livros, revistas e publicações têm sido produzidos para levar aos pais e educadores um saber mais técnico sobre a adolescência. $O$ interesse de nosso estudo se colocou exatamente na concepção de adolescência apresentada nestas publicações e se propôs a uma análise crítica, indicando as conseqüências de concepções naturalizantes, tanto na prática educativa quanto na fragilidade das políticas públicas neste setor. Com base na perspectiva sócio-histórica em Psicologia, pretendeu-se contribuir para a divulgação e desenvolvimento de uma concepção de adolescência como produção social, indicando possibilidades de novas práticas e subsídios para a construção de políticas públicas para a juventude, levando-se em consideração a adolescência a partir de sua natureza histórica.

Palavras-chave: adolescência; políticas públicas; juventude

\section{Adolescence as a Social Construction - a Research on the Concept On Books Applied to Parents and Educators}

\begin{abstract}
The adolescence has been a society interest theme and consequently Psychology is giving it a very important space not only in the field of Development Psychology but on fields of Education and Social Psychology as well. Books, magazines and publications have being produced in order to give parents and educators a more technical knowledge on the adolescence theme. The interest of our research is related to the exact conception of adolescence that those publications present and considers its critical analysis indicating the consequences of naturalizing conceptions as much as in the educative practice as in the fragility of public policies in that sector. Based on social-historical perspective in psychology, it was intended to contribute to the spreading and development of an adolescence conception that takes it as a social production indicating possibilities of new practices and allowances to the construction of youth public policies that considers adolescence its social historical nature.
\end{abstract}

Keywords: Adolescence, Public Policies, Youth

\section{Adolescencia como construcción social: estudio sobre libros destinados a padres y educadores}

\section{Resumen}

La adolescencia ha sido un tema de interés en la sociedad y por consiguiente la Psicología le ha dedicado un espacio importante, tanto en el campo de la Psicología del Desarrollo como también en el área de la Psicología de la Educación y la Psicología Social. Libros, revistas y publicaciones han sido producidos para pasarle a los padres y educadores un saber más técnico sobre la adolescencia. El interés de nuestro estudio se encajó exactamente en la concepción de la adolescencia que estas publicaciones presentan, y se propone un análisis clínico de ellas, indicando las consecuencias de concepciones naturalizantes, tanto en la práctica educativa como en la fragilidad de las políticas públicas en este sector. Con base en la perspectiva socio-histórica en Psicología se pretendió contribuir para la divulgación y desarrollo de una concepción de adolescencia que la tome como producción social, indicando posibilidades de nuevas prácticas y subsidios para la construcción de políticas públicas para la juventud que vea a la adolescencia a partir de su naturaleza histórica.

Palabras clave: adolescencia, políticas públicas, juventud. 
A Psicologia e outras áreas da ciência têm se dedicado ao estudo da adolescência, buscando contribuir a qualificação dos trabalhos profissionais com estes jovens e a compreensão dos "problemas" sociais envolvendo a juventude. Livros, revistas e publicações têm sido produzidos para levar aos pais e educadores um saber mais técnico sobre a adolescência, instrumentando profissionais e pais a lidarem com eles de modo mais competente e eficaz. Ou seja, a adolescência tem se tornado um tema de interesse para o qual se tem criado um saber específico. Em publicação recente, Aguiar, Bock e Ozella (200I) apresentam uma síntese de estudos sobre o conceito de adolescência. Os autores afirmam a marca indelével da Psicanálise na construção do conceito e identificam no início do século $X X$, com Stanley Hall, a introdução da adolescência como objeto de estudo da Psicologia. Concebida como uma fase da vida do homem, ela foi identificada como uma etapa marcada por tormentos e conturbações vinculadas à emergência da sexualidade.

Foi Erickson (1976), no entanto, que institucionalizou a adolescência. Apresentou-a a partir do conceito de moratória e a caracterizou como uma fase especial no processo do desenvolvimento, na qual a confusão de papéis, as dificuldades para estabelecer uma identidade própria a marcavam como “...um modo de vida entre a infância e a vida adulta" (Erickson, 1976, p.I28).

Erickson foi seguido por muitos autores. Na América Latina cabe destacar Aberastury e Knobel (1989) que, com sua obra, tornaram-se referência para profissionais de várias áreas. Knobel introduziu a noção de "síndrome normal da adolescência", caracterizada por uma sintomatologia que inclui: "I) busca de si mesmo e da identidade; 2) tendência grupal; 3) necessidade de intelectualizar e fantasiar; 4) crises religiosas, que podem ir desde o ateísmo mais intransigente até $\circ$ misticismo mais fervoroso; 5) deslocalização temporal, em que o pensamento adquire as características de pensamento primário; 6) evolução sexual manifesta, desde o auto-erotismo até a heterossexualidade genital adulta; 7) atitude social reivindicatória com tendências anti ou associais de diversa intensidade; 8) contradições sucessivas em todas as manifestações da conduta, dominada pela ação, que constitui a forma de expressão conceitual mais típica deste período da vida; 9) uma separação progressiva dos pais; e 10) constantes flutuações de humor e do estado de ânimo" (Knobel, 1989, p.29)

Note-se que as concepções correntes, até então, concebiam a adolescência como uma etapa natural do desenvolvimento, tendo um caráter universal e abstrato. Inerente ao desenvolvimento humano, a adolescência não só foi naturalizada, mas também percebida como uma fase difícil, uma fase do desenvolvimento, semi-patológica, que se apresenta carregada de conflitos "naturais". A cultura aparece apenas como molde da expressão de uma adolescência natural que, por outro lado, sofre com a pressão exercida pela sociedade atual, a qual impõe a moratória ao adolescente pela dificuldade e demora para ingressar no mundo do trabalho. Nessas construções teóricas, encontramos a visão de que o homem é dotado de uma natureza, dada a ele pela espécie e, conforme cresce, se desenvolve e se relaciona com o meio, atualizando características que já estão lá, pois são de sua natureza. A adolescência pertence a esse conjunto de aspectos. Suas características são decorrentes do "amadurecer"; são hormônios jogados na circulação sanguínea e o desabrochar da sexualidade genital os fatores responsáveis pelo aparecimento da sintomatologia da adolescência normal.

Inúmeros estudos têm sido feitos sem que se apresente uma nova versão ou conceituação para a adolescência capaz de superar a visão naturalizante.

David Levinsky (1995) conceitua a adolescência como sendo uma fase do desenvolvimento evolutivo, em que a criança gradualmente passa para a vida adulta de acordo com as condições ambientais e de história pessoal. Levinsky entende a adolescência como de natureza psicossocial, no entanto, ao debater o surgimento da fase, vincula-a à puberdade e ao desenvolvimento cognitivo. Para o autor, a adolescência é caracterizada pelo modo com que a sociedade a representa, ou seja, nas sociedades modernas ela é mais lenta e dolorosa e já nas primitivas, ela era agilizada e atenuada pelos ritos de passagem e pela maior facilidade em participar do mundo adulto. Ao lado desta leitura mais social e cultural, Levinsky refe- 
re-se às crises universais na adolescência ligadas ao tabu do incesto. A sociedade e a cultura agravam a crise dos adolescentes com sua hipocrisia e paradoxos, introjetando no adolescente seus defeitos de forma projetiva.

Içami Tiba (1985), outro autor brasileiro de grande repercussão na área, define a adolescência como uma fase do desenvolvimento não estabilizada por tempo de duração, mas que sempre tem início após a puberdade, e nada mais é do que a maturação filogeneticamente programada do aparelho reprodutor. A adolescência seria uma fase de reestruturação do "núcleo do eu", quando as estruturas psíquicas/corporais, familiares e comunitárias sofrem mudanças conflitantes. Lutos e fragilidades psíquicas afloram neste período em que o adolescente tende a buscar autonomia, liberdade, prazer e status, agindo de maneira compulsiva e agressiva. A cultura aparece como reflexo dos aspectos corporais e psicológicos (naturais), assim como os modos de produção da vida também não são vistos como constitutivos da adolescência.

Outeiral (1994) é outro autor brasileiro utilizado como referência na área. Para ele, a adolescência é uma fase do crescimento humano que se caracteriza pela definição da identidade. Seu início se dá com as transformações do corpo, ou seja, com a puberdade, e se estende até que a maturidade e a responsabilidade social sejam adquiridas pelo indivíduo. A adolescência é dividida, por Outeiral, em três fases: na primeira, o jovem vivencia uma passividade em relação as suas transformações corporais, criando-se a partir daí um sentimento de impotência frente ao mundo e à realidade. $\mathrm{Na}$ segunda, a crise se dá por um choque entre gerações, já que a estrutura familiar vivida hoje é muito diferente da estrutura vivida por seus pais. A busca da independência é o foco central, incluindo a busca da definição sexual. $\mathrm{Na}$ terceira e última fase, a busca se dá pela identidade profissional e inserção no mercado de trabalho, ou seja, a busca de reconhecimento pela sociedade e a independência financeira.

Para Domingues e Alvarenga (1991), a adolescência é uma fase para o ingresso na vida adulta e que, pelo fato de não haver precisão sobre seu início e seu término, demarcados através de rituais socialmente reconhecidos, a adolescência é vivida sob forma de imensa contradição e ambigüidade. No mais, é um fenômeno das sociedades modernas surgidas no final do século $X I X$ e início do século $X X$ com o incremento da urbanização e industrialização, emergindo entre a infância e a vida adulta como um período intermediário. Segundo as autoras, vivenciar experiências com seus grupos de pares seria a maior aspiração, pois deste modo deixam de ser crianças, estabelecendo novas relações com seus pais e familiares.

Melucci (1997) afirma que a adolescência é a idade da vida em que se começa a enfrentar o tempo como uma dimensão significativa e contraditória da identidade. Nesta idade, o futuro é visto como um conjunto de possibilidades, prevalecendo sua orientação. Essas possibilidades podem se tornar fantasmas, por não haver tempo para realizá-las.

Bajoit e Franssen (1997) relacionam a adolescência à experiência no mercado de trabalho, entendo-a como um momento decisivo na definição da identidade do jovem. Apontam que, no entanto, a referência ao trabalho tradicional se tornou impraticável por sua dificuldade de inserção, sendo esta degradação vivida como crise. Eles realizaram um estudo interessante, mostrando como em cada grupo social esta crise é vivida diferentemente. Em jovens do meio popular a representação do trabalho está mais ligada a normas tradicionais e o desemprego é vivido como exclusão; já, entre os jovens da classe média desvalorizam o trabalho assalariado preferindo um projeto de autorealização e o desemprego é vivido como tempo para redefinição de projetos existenciais.

Peralva (1997) coloca a adolescência como uma fase do crescimento, provindo da cristalização das "idades da vida", sendo que estas fases aparecem hierarquizadas. $O$ velho se impõe sobre o novo; $\circ$ passado informa o futuro e esta definição cultural da ordem moderna define as relações entre adultos e jovens, estabelecendo o lugar no mundo para cada idade da vida. O jovem é aquele que se integra mal, resiste à socialização, se desvia do padrão, sendo a representação do desvio.

Estudos como os de Becker (1989) e Calligaris (2000) trouxeram elementos culturais para a leitura da adolescência, mas não superaram a visão abstrata do 
conceito. Becker (1989) propõe que olhemos a adolescência como "a passagem de uma atitude de simples espectador para uma outra ativa, questionadora. Que inclusive vai gerar revisão, autocrítica, transformação" (Becker, 1989, p. 10). A adolescência concebida como transformação, toma da sociedade e da cultura, as formas para se expressar.

Partindo da adolescência como moratória, Calligaris (2000) analisa, de forma rica, as dificuldades que os jovens vão encontrar na sociedade para se inserirem, nesta fase denominada adolescência, fase esta instituída na nossa cultura e que, para o autor, só se tornou problemática, merecendo destaque em nossos estudos, quando "o olhar adulto não reconheceu nelas os sinais da passagem para a vida adulta" (Calligaris, 2000, p.20). Calligaris avança na direção da superação do conceito abstrato afirmando: “...Numa sociedade em que os adultos fossem definidos por alguma competência específica, não haveria adolescentes, só candidatos e uma iniciação pela qual seria fácil decidir: sabe ou não sabe, é ou não é adulto. Como ninguém sabe direito o que é um homem ou uma mulher, ninguém sabe também o que é preciso para que um adolescente se torne adulto. $O$ critério simples da maturação física é descartado. Falta uma lista estabelecida de provas rituais. Só sobram então a espera, a procrastinação e o enigma, que confrontam o adolescente - este condenado a uma moratória forçada de sua vida - com uma insegurança radical..." (Calligaris, 2000, p.2I). O autor caminha investigando as dificuldades dos jovens em obterem da sociedade informações que lhes possibilitem superar a moratória e finalmente conclui que, o adolescente, na falta de definição 'do que ser', torna-se um intérprete dos desejos adultos. "...o adolescente é levado inevitavelmente a descobrir a nostalgia adulta de transgressão, ou melhor, de resistência às exigências antilibertárias do mundo. Ele ouve, atrás dos pedidos dos adultos, um 'Faça o que eu desejo e não o que eu peço'E atua em conseqüência" (Calligaris, 2000, p.28). Assim, Calligaris retoma uma concepção abstrata da adolescência: a fonte da adolescência está nos desejos adultos e não nas formas de vida.

Tanto em uma versão quanto em outra, a adolescência fica concebida como uma fase difícil, uma fase problemática da vida, que deve ser superada. As características específicas da adolescência (se é que existem) são tomadas como negativas ou como "bobagens da idade".

Além disso, pode-se apontar como um elemento importante de crítica o fato da adolescência, conceituada no âmbito da Psicologia, estar fundamentada em um único tipo de jovem, como apontou Santos (1996): homem-branco-burguês-racional-ocidental, oriundo em geral da Europa ou dos Estados Unidos. Os estudos, em sua maioria, são feitos a partir da existência desses jovens, não se buscando em outros grupos a suas idiossincrasias; ao contrário, como se toma a adolescência como universal e natural não há qualquer necessidade de buscar outros grupos para completar os estudos. Esses são buscados apenas para a aplicação dos conceitos já construídos.

Criticar a perspectiva naturalizante se torna uma necessidade, pois a Psicologia, ao desenvolver perspectivas naturalizantes, deixa de contribuir para leituras críticas da sociedade e para a construção de políticas adequadas para a juventude, responsabilizando, com sua leitura, o próprio adolescente e seus pais pelas questões sociais que envolvem jovens, como a violência e a drogadição.

O objetivo deste estudo foi de fazer uma revisão crítica sobre a concepção de adolescência que tem sido divulgada, em nossa sociedade, através de livros e publicações destinadas a pais e educadores. $O$ estudo pretende também analisar as orientações de condutas que têm sido decorrentes desta concepção. Pretende-se contribuir para a superação de concepções naturalizantes que têm marcado o conceito e reapresentá-lo, a partir da perspectiva sócio-histórica em Psicologia, como uma produção social, assim como indicar subsídios para uma "nova" prática com adolescentes e para a construção de políticas públicas que tomem o jovem como ator social importante.

A análise crítica que se pretende fazer, sobre as produções conceituais da adolescência, parte da perspectiva sócio-histórica em Psicologia. Uma perspectiva que, tendo base no marxismo, entende que $\circ$ indivíduo se desenvolve a partir de sua relação com o mundo social e cultural. "...o homem se torna mais individual e pode desenvolver uma atividade totalmen- 
te autônoma, necessariamente através de um grande desenvolvimento das relações sociais, da realidade humana objetivada e com a plena socialização do indivíduo" (Duarte, 1993, p.157).

Leontiev, psicólogo soviético, em seu texto "O Homem e a Cultura", apresenta com clareza estas idéias. "Podemos dizer que cada indivíduo aprende a ser um homem. O que a natureza lhe dá quando nasce não lhe basta para viver em sociedade. É-lhe ainda preciso adquirir o que foi alcançado no decurso do desenvolvimento histórico pela sociedade humana" (Leontiev, 1978, p.267).

Em estudo anterior sobre o fenômeno psicológico, Bock (200I) encontrou duas visões antagônicas denominando-as de "visão liberal" e "visão sócio-histórica", acompanhando as grandes vertentes do pensamento positivista e marxista de nosso tempo. Estas visões são referência para o estudo que ora se apresenta.

A concepção sócio-histórica se contrapõe à concepção de base liberal, na qual o homem é concebido a partir da idéia de natureza humana. Seria possuidor de uma natureza que permite com seu desenvolvimento que se torne homem, tal qual o conhecemos. Haveria assim, um homem apriorístico dentro de cada um de nós, um homem em potencial com seu desenvolvimento previsto pela sua própria condição de homem. Esse desenvolvimento pode ser facilitado ou dificultado pelo meio externo, social e cultural. $O$ homem é livre e dotado de potencialidades naturais que necessitam de condições adequadas para se atualizarem, se concretizarem, permitindo a realização daquilo que é potencial, dada a natureza humana.

Quanto à relação do homem com a sociedade, encontramos a visão de que a sociedade é sempre algo externo e independente dele e essa deve estar organizada para facilitar e contribuir com o seu desenvolvimento do potencial. A sociedade é vista como algo contrário às tendências naturais do homem e é compreendida e estudada sempre como algo que é externo e estranho à natureza humana, pois não faz parte da Natureza. Suas forças são contrárias às tendências humanas.

$\mathrm{Na}$ visão sócio-histórica, utilizada como referência, o Homem é visto como um ser histórico, isto é, um ser constituído no seu movimento e ao longo do tempo, pelas relações sociais, pelas condições sociais e culturais engendradas pela humanidade. Um ser que tem características forjadas pelo tempo, pela sociedade e pelas relações, imerso nas relações e na cultura das quais retira suas possibilidades de ser e suas impossibilidades. Um homem que está situado no tempo histórico e que terá sua constituição psíquica determinada por essa condição. A relação indivíduo/ sociedade é vista como uma relação dialética, na qual um constitui o outro. $O$ homem se constrói ao construir sua realidade. A sociedade passa a ser imprescindível para a compreensão da forma de se apresentar do homem; do humano. Não se pode conhecer o humano se não for pela sua relação com as formas de vida e as relações sociais. O próprio fenômeno psicológico é histórico, permitindo que se entenda o que está aí como padrão, como algo mutável, resultante de um determinado padrão de relações e de critérios dominantes que respondem a interesses sociais de imposição de uma determinada visão de saúde.

O fenômeno psicológico deve ser entendido como construção no nível individual do mundo simbólico que é social. $O$ fenômeno deve ser visto como subjetividade, concebida como algo que se constituiu na relação com o mundo material e social, mundo este que só existe pela atividade humana. Subjetividade e objetividade se constituem uma à outra sem se confundirem. A linguagem é mediação para a internalização da objetividade, permitindo a construção de sentidos pessoais que constituem a subjetividade. $O$ mundo psicológico é um mundo em relação dialética com o mundo social. Conhecer o fenômeno psicológico significa conhecer a expressão subjetiva de um mundo objetivo/coletivo; um fenômeno que se constitui em um processo de conversão do social em individual; de construção interna dos elementos e atividades do mundo externo. Conhecê-lo desta forma significa retirá-lo de um campo abstrato e idealista e dar a ele uma base material vigorosa. Permite ainda que se supere definitivamente visões metafísicas do fenômeno psicológico que o conceberam como algo súbito, algo que surge no homem, ou melhor, algo que já estava lá, em estado embrionário, e que se atualiza com o amadurecimento humano. 


\section{A adolescência da perspectiva sócio-histórica}

$A$ adolescência não é vista aqui como uma fase natural do desenvolvimento e uma etapa natural entre a vida adulta e a infância. A adolescência é vista como uma construção social com repercussões na subjetividade e no desenvolvimento do homem moderno e não como um período natural do desenvolvimento. É um momento significado, interpretado e construído pelos homens. Estão associadas a ela marcas do desenvolvimento do corpo. Essas marcas constituem também a adolescência enquanto fenômeno social, mas o fato de existirem enquanto marcas do corpo não deve fazer da adolescência um fato natural.

Há muitas outras características que constituem a adolescência; além disso, as marcas corporais são significadas socialmente, não sendo tomadas no conceito de adolescência em si, como características do corpo e, portanto, naturais. Exemplo disto são os seios na menina e a força muscular nos meninos. Sabemos que os seios e o desenvolvimento da massa muscular acontecem na mesma fase da adolescência. Mas, a menina que tem seus seios se desenvolvendo não os vê, sente e significa como possibilidade de amamentar seus filhos no futuro, o que seria vê-los como naturais. Com certeza, em algum tempo ou cultura, isso já foi assim. Hoje, os seios tornam as meninas sedutoras e sensuais. Esse é o significado atribuído atualmente. A força muscular dos meninos já foi significada como possibilidade de trabalhar, guerrear e caçar. Hoje é beleza, sensualidade e masculinidade.

Da mesma forma, o jovem não é algo "por natureza". Como parceiro social está ali, com suas características, interpretadas nessas relações,, o modelo para sua construção pessoal. Construídas as significações sociais, os jovens têm então a referência para a construção de sua identidade e os elementos para a conversão do social em individual.

A abordagem sócio-histórica, ao estudar a adolescência, não faz a pergunta "o que é a adolescência", mas, "como se constituiu historicamente este período do desenvolvimento". Isto porque para esta abordagem, só é possível compreender qualquer fato a partir da sua inserção na totalidade, na qual este fato foi produzido, totalidade essa que o constitui e lhe dá sentido. Responder o que é a adolescência implica em buscar compreender sua gênese histórica e seu desenvolvimento.

Adélia Clímaco (199I) traz em seus estudos vários fatores sociais-econômicos e culturais que nos possibilitam compreender como surgiu a adolescência. Retomaremos aqui, brevemente, estes fatores apontados pela autora. A sociedade moderna, com suas revoluções industriais, gerou grandes modificações nas formas de vida. Com as revoluções industriais, o trabalho se sofisticou, do ponto de vista tecnológico e passou a exigir um tempo prolongado de formação, adquirida na escola, reunindo em um mesmo espaço os jovens e afastando-os do trabalho por algum tempo. Além disso, o desemprego crônico/ estrutural da sociedade capitalista trouxe a exigência de retardar o ingresso dos jovens no mercado e aumentar os requisitos para este ingresso, o que era respondido pelo aumento do tempo na escola.

A ciência, por outro lado, resolveu muitos problemas do homem e ele teve a sua vida prolongada, 0 que trouxe desafios para a sociedade, em termos de mercado de trabalho e formas de sobrevivência. Estavam dadas as condições para que se mantivesse a criança mais tempo sob a tutela dos pais, sem ingressar no mercado de trabalho. Mantê-las na escola foi a solução. A extensão do período escolar e o conseqüente distanciamento dos pais e da família e a aproximação de um grupo de iguais foram conseqüências destas exigências sociais. A sociedade então assiste à criação de um novo grupo social com padrão coletivo de comportamento -a juventude/a adolescência.

A adolescência se refere, assim, a esse período de latência social constituída a partir da sociedade capitalista gerada por questões de ingresso no mercado de trabalho e extensão do período escolar, da necessidade do preparo técnico. Essas questões sociais e históricas vão constituindo uma fase de afastamento do trabalho e o preparo para a vida adulta. As marcas do corpo, as possibilidades na relação com os adultos vão sendo pinçadas para a construção das significações.

Podemos prosseguir no caminho de Clímaco (199I) e postular a hipótese de que os jovens passaram, então, a estar colocados em uma nova condição social: o jovem, apesar de possuir todas as condições 
cognitivas, afetivas e fisiológicas para participar do mundo adulto, estava desautorizado a isso, devendo permanecer em um compasso de espera para esse ingresso; vai ficando distante do mundo do trabalho e distante também das possibilidades de obter autonomia e condições de sustento. Vai aumentando o vínculo de dependência do adulto, apesar de já possuir todas as condições para estar na sociedade de outro modo. Essa contradição vivida pelos jovens foi responsável pelo desenvolvimento de uma série de características que refletem a nova condição social na qual se encontram. Estas características são aquelas, descritas pela Psicologia, mas que não são tomadas aqui como naturais e sim, constituídas no processo histórico e social: crises de identidade e busca de si mesmo; tendência grupal; necessidade de intelectualizar e fantasiar; atitude rebelde; onipotência e outras. As condições sociais nas quais se encontram os jovens são como fonte mobilizadora e geradora da chamada "adolescência". A moratória na qual se encontram os jovens não é um período necessário do seu desenvolvimento e sim, um período no qual o mundo adulto considerou necessário colocar seus jovens para poderem, os adultos, estar mais tempo no mercado de trabalho e, os jovens mais bem preparados para responderem às exigências do novo mundo do trabalho tecnológico.

Na retomada histórica, Levi e Schmitt (1996) permitiram que compreendêssemos que a juventude, nas várias épocas históricas e nas civilizações, adquiriu significados distintos. Na sociedade grega, os homens eram a força física e os jovens tinham essa força em sua plenitude e vigor e eram treinados para se tornarem cidadãos de forma integral e a juventude significou esta etapa de preparação. No mundo romano, a caça, a briga, a corrida e a nudez caracterizaram a juventude. Às mulheres estava destinada a criação dos filhos e os cuidados da casa, não exigindo preparações muito sofisticadas. Para os homens existiam vários rituais de preparação. Para a juventude judaica na Europa, os 30 anos de idade marcavam o ápice da força e responsabilidade plena. $O$ casamento era a atividade mais importante para marcar a vida adulta, a qual possuía status, prestígio e possibilidades de acesso a direitos. As "marcas" da juventude e seus significa- dos se modificaram no tempo e nas diversas civilizações: força física, cortesia e amor, guerra e caça, jogos, proezas, responsabilidades, transgressões; 20 anos ou 30 anos; uma etapa curta ou longa de passagem para a vida adulta, a adolescência não foi a mesma coisa sempre.

Ao estudar a construção histórica da infância e da adolescência, em seu trabalho de mestrado, Santos (1996) cita Morin (1986; 1990) que acredita que a adolescência, enquanto "classe de idade" surgiu na civilização do século $X X$, nos anos 50 , e hoje, é, praticamente, fenômeno universal. Para ele, a adolescência nasce nos Estados Unidos e depois se espalha rapidamente pelo mundo ocidental, países do leste europeu e centros urbanos do Terceiro Mundo. As explicações para seu surgimento são o declínio da família como unidade de produção e mudança do padrão de vida agrário para o urbano. As ocupações já não passavam de pai para filho, o que criou um gap entre a experiência dos pais e a dos filhos, transformando a idade de teens em época da vida dedicada à escolha profissional. Essa visão ganha força social e passa a ser respaldada por normas legais de proibição do trabalho neste período da vida e de compulsoriedade da educação escolar. Essas medidas acabam conferindo status jurídico para a existência da adolescência como categoria de idade. "A indústria cultural se apropria dos valores e atributos próprios desta fase da vida e contribui para criar uma cultura adolescente. Desse modo, as mudanças econômicas, familiares e culturais transformam a experiência de crescimento e a adolescência tornou-se um importante estágio na biografia individual e, mais do que isso, em um conjunto etário nas sociedades modernas ocidentais" (Santos, 1996, p.154).

Outro fator para o desenvolvimento da adolescência é a ausência de ritos institucionalizados de passagem, descontinuidade entre o mundo do adulto e da criança. Faltam modelos para o desempenho de papéis, o que provoca uma dificuldade de identificação da criança, contribuindo para produzir conflitos em uma fase que passa a ser de transição. Santos (1996) afirma que só pode haver adolescência como tempo de conflito onde o mecanismo de iniciação, transformando a criança em adulto, se deslocou ou decompôs-se e onde 
se desenvolveu uma zona de cultura e de vida que não está engajada, integrada na vida adulta.

Adolescência para Santos (1996) está identificada com escola, com aumento de tempo na escola, com a mudança da instituição escolar e a extensão progressiva do período de aprendizagem; tudo isto deu consistência e visibilidade à condição infanto-juvenil (Santos, 1996, p.157). Alguns grupos sociais que ficam excluídos da escola e ingressam cedo no mundo do trabalho se "adultizam" e não têm acesso à adolescência, enquanto uma condição social.

São muito importantes as contribuições de Clímaco (1991) e Santos (1996), no sentido de produzir uma clareza sobre a concepção de que a adolescência é criada, na sociedade moderna, por exigências dessa sociedade. Constitui-se na relação com os adultos, representantes dessa sociedade. As características se constituem na medida em que os jovens, colocados nessa nova condição, desenvolvem suas formas de inserção nessa relação.

Importante registrar que, na medida em que esse fato social da adolescência se configura, tomando contornos mais claros, a sociedade como um todo registra e dá significado a esse momento. A ciência a estuda, a conceitua, a expressa em livros e descreve suas características (tomadas como se fossem naturais da idade). A sociedade reconhece, então, uma fase do desenvolvimento de seus filhos e jovens e atribui-Ihe significados; espera algumas condutas de seus filhos e jovens.. A adolescência se instala de forma inequívoca na sociedade. Os jovens que não possuíam referências claras para seus comportamentos utilizam, agora, essas características como fonte adequada de suas identidades: são agora adolescentes.

Não há nada de patológico; não há nada de natural. A adolescência é social e histórica. Pode existir hoje e não existir mais amanhã, em uma nova formação social; pode existir aqui e não existir ali; pode existir mais evidenciada em um determinado grupo social, em uma mesma sociedade (aquele que fica mais afastado do trabalho) e não tão clara em outros gru- pos (os que se engajam no trabalho desde cedo e adquirem autonomia financeira mais cedo). Não há uma adolescência, enquanto possibilidade de ser; há uma adolescência enquanto significado social, mas suas possibilidades de expressão são muitas.

\section{O Estudo}

O estudo se desenvolveu a partir da análise de textos publicados sobre adolescência, destinados aos pais e professores. Analisamos o conceito de adolescência presente nestes textos, através da sua sistematização em categorias que nos permitiram uma aproximação maior do discurso.

A escolha dos textos se deu a partir de um levantamento que:

- considerou livros destinados a pais e professores sobre a adolescência que, na opinião de vendedores em grandes livrarias, eram considerados livros de alta vendagem.

- contemplou publicações de autores brasileiros e estrangeiros (publicados em português) indicados pelos livreiros. $O$ livro estrangeiro indicado era americano, não havendo nas livrarias, à disposição, no momento, livros de outros países. Os livros deveriam, em seu conteúdo, conter trechos que permitissem acesso ao conceito de adolescência do autor e indicações de conduta de como lidar com os adolescentes e terem sido publicados nos últimos 10 anos (1992 em diante)'.

Construímos, a partir dos textos, categorias para a sistematização dos conteúdos. As categorias permitiram organizar os conteúdos dos textos, tornando mais visível a concepção. Quatro categorias para sistematizar o conteúdo foram, então, elaboradas:

I) Descrição das características e comportamento do jovem;

2) Descrição da relação dos jovens com adultos;

3) Explicação da adolescência: Gênese e

4) Regras e Orientações.

\footnotetext{
' Waldman, Larry - E agora? Tenho um filho adolescente, Ed. Mercuryo, 1997, São Paulo; Tiba, Içami - Disciplina: limite na medida certa- Ed. Gente, 1996, São Paulo; Zagury, Tânia - O Adolescente por ele mesmo: orientação para pais e educadores - Ed. Record, 1996, Rio de Janeiro; e Zagury, Tânia - Limites sem trauma- construindo cidadãos - Ed. Record, I2ª edição, 200I, Rio de Janeiro
} 
Voltamos aos textos e fomos numerando as frases na seqüência de cada texto. Montamos então, quatro quadros, um para cada livro, no qual colocamos as frases nas suas categorias, numeradas em sua seqüência, permitindo ao leitor o conhecimento exato da seqüência do texto. A sistematização e a análise foram feitas mantendo os livros separados um do outro, permitindo o conhecimento de cada um em sua visão e conceito.

Em seguida, pudemos iniciar a análise de cada livro/capítulo, em cada uma das categorias; quais e como estavam apresentadas as características e o comportamento dos adolescentes; qual a gênese apontada pelo texto para essas características; como estava apresentada a relação dos adolescentes com os adultos e quais as orientações que eram apresentadas para os pais e professores. Em relação às quatro categorias indicadas foram feitas sínteses de cada livro.

\section{As concepções que encontramos nos livros}

Para Waldman (1997, p. 23-56), a adolescência acontece sem que se escolha ou saiba. É marcada por características universais e pela busca da independência e identidade. Antes desta idade, isso não ocorre e nem mesmo a forma de relação dos pais com os filhos em nossa sociedade é pensado como tendo algo a ver com o que se busca nesta fase. $O$ adolescente é visto de forma negativa, como alguém sem controle, que não consegue decidir; as palavras utilizadas por Waldman para caracterizá-los são negativas: retalia, agride, resiste; malvados, parecem doidos. São vistos como incapazes.

Quanto à relação com os adultos, os pais são vítimas. $O$ próprio nome do livro demonstra esta posição: $E$ agora? Tenho um filho adolescente. Mostra que os pais são despreparados para conviverem com os adolescentes. Resistem a perder o controle sobre os filhos.

Quanto à gênese da adolescência esta é natural, decorrente da produção de hormônios e mudanças corporais e intelectuais. A adolescência é ainda imaturidade do ser humano que está em desenvolvimento e, por isso, é uma fase que passa.

O autor então, vê as relações com os pais como luta, mas os pais devem ser capazes de tolerância e compreensão. $O$ adolescente é tomado como um ini- migo para o qual a melhor arma é a compreensão. $O$ adulto é valorizado como capaz da aceitação e da paciência e o jovem é tomado como alguém sem controle ou maturidade. A adolescência passa e tudo fica resolvido. Não há o que se fazer enquanto a adolescência é vivida; resta ser tolerante.

Tiba (1996, p. 77-86) adota visão naturalizante e adaptativa ao caracterizar a adolescência. $O$ adolescente é visto como um ente acima e além dos indivíduos e das relações. As características são tomadas como universais e inevitáveis, respondem a necessidades.

Quanto à relação com os adultos, este é estável, pronto e acabado, ao contrário do adolescente. $\mathrm{O}$ conflito na relação é tomado como natural e o adulto deve aprender a conviver bem com isso.

Quanto à gênese da adolescência, Tiba é taxativo na sua visão; há um padrão natural. A adolescência simplesmente acontece. Há, no entanto, uma referência à saúde que permite que o conflito não seja tão intenso. O que é um filho saudável? Não se sabe pelo texto. Sabe-se que a saúde reduz a intensidade do conflito (necessário e inevitável).

A orientação oferecida para os adultos é de tolerância e compreensão, supondo que a adolescência é natural e não tem jeito a não ser tolerar. Zagury (200I, p. I45-163) apresenta a adolescência com características negativas, "como capacidade inesgotável de se opor, insegurança e baixa auto-estima, certa dose de depressão; precisam de amor, são jovens e estão aprendendo". Todas estas características são atribuídas à idade. São negativas no sentido de incompletude e imaturidade e por não serem características desejadas.

$\mathrm{Na}$ relação, os pais precisam ser tolerantes e dar amor aos filhos adolescentes e devem se impor como autoridades. Há uma grande preocupação em orientar os pais para se manterem hierarquicamente superiores em relação a seus filhos adolescentes.

O texto não traz qualquer informação sobre a gênese da adolescência. Como ela surge? Como surgem todas as características da adolescência? Não há posicionamento sobre isso, o que demonstra uma visão naturalizante.

Quanto às orientações e regras, Zagury entende que o jovem deve ser aceito, tolerado e compreendi- 
do. A autoridade do adulto serve para dar segurança e amor. Para a autora, autoridade está diferenciada de controle, sendo a autoridade muito valorizada como necessária para enfrentar o filho adolescente que faz as coisas erradas e estas não devem ser toleradas. De resto, a orientação básica é mesmo a tolerância e a autoridade.

Em um segundo livro de Zagury (1996, p. 23-32), a descrição das características dos jovens é extensa e rica. Características de comportamento social e, principalmente, psicológicas. São tomadas e apresentadas como características de uma fase do desenvolvimento, universais e naturais, pois todos os jovens nesta fase apresentarão estas características. Interessante relacionarmos algumas: desenvolvimento físico, intelectual e afetivo, amadurecimento sexual, mudanças sociais, tendência à imitação, tendência a buscar novas respostas, onipotência pubertária, grande apetite, insegurança, busca de identidade, confusão, medo, preocupação social, sonho, contradição, serenidade, instabilidade, emoções contraditórias e sentem-se imortais.

A relação do adulto com o jovem é apresentada como uma relação difícil, pois os pais não querem perder o lugar de referência e os filhos estão em uma fase complexa. A gênese da adolescência está no desenvolvimento do raciocínio que permite o aumento da capacidade intelectual e, portanto, gera independência intelectual. No entanto, o desenvolvimento intelectual não parece ser responsável por todas as características da adolescência.

Quanto às orientações e regras, os adultos devem compreender a adolescência como uma fase do desenvolvimento. A adolescência é complexa, mas passa. Os pais não devem infantilizar os filhos e devem estabelecer com clareza as regras de convivência. Os jovens não devem ser poupados no que diz respeito a assumirem suas responsabilidades. Firmeza e, compreensão é um bom remédio para esperar a adolescência passar.

\section{Discutindo os dados e esboçando uma conclusão \\ Características da adolescência:}

A adolescência foi apresentada, nos 4 livros estudados, por meio de elementos, em geral, negativos.
Negativos porque são características desvalorizadas na sociedade; porque aparecem como incompletude, imaturidade, algo que ainda não acabou de acontecer e de se desenvolver. As características positivas que aparecem na descrição da adolescência são tomadas como algo "da fase", fruto da imaturidade. É definida em oposição com o adulto, o qual aparece como a meta deste desenvolvimento; como o estágio a ser atingido; como a etapa que apresenta as características que a adolescência ainda não possui. Adolescência é fase do desenvolvimento e se encaminha para a vida adulta. Por isso a adolescência aparece como fase passageira.

Como fase do desenvolvimento, as características são universais e inevitáveis. Tomadas como fruto do desenvolvimento são também naturalizadas. É da natureza do homem e de seu desenvolvimento passar por uma fase como a adolescência. As características desta fase, tanto biológicas, quanto psicológicas são naturais. Rebeldia, desenvolvimento do corpo, instabilidade emocional, tendência à bagunça, hormônios, tendência à oposição, crescimento, desenvolvimento do raciocínio lógico, busca da identidade, busca de independência, enfim todas as características são equiparadas e tratadas da mesma forma, porque são da natureza humana.

\section{Relações dos jovens com os adultos:}

A relação é apresentada como uma relação difícil e conflituosa, uma luta, pois os jovens querem se libertar dos pais e estes não querem perder o controle dos filhos. Os critérios são diferentes, os gostos, as vontades, as regras, enfim, tudo é apresentado como sendo muito diferente entre pais e filhos. A diferença surge das características dos jovens que, por natureza, se opõem ao que está estabelecido pelos pais. É característica da adolescência a oposição aos pais e ao mundo adulto.

\section{Explicação da adolescência: gênese}

É, a rigor, uma incógnita. Poucas referências são feitas à gênese da adolescência, não se buscando uma visão clara da gênese dos fenômenos. Como surgem estas características? $\mathrm{Na}$ verdade, não se tem nenhuma leitura sobre isto porque se crê que a adolescên- 
cia é natural; é uma fase do desenvolvimento, não sendo necessário se falar da gênese; a ênfase recai sobre a descrição das características que estão em potencial na natureza humana e vão se atualizando conforme há desenvolvimento e crescimento. Assim, não há leitura social alguma. As relações com o mundo social e adulto aparecem somente como interferência; interferem mas não constituem. As diferenças existentes entre os adolescentes se dão devido às influências do meio que facilitam ou dificultam o desabrochar daquilo que é potencial.

\section{Orientações e regras:}

A maior parte das orientações está dada aos adultos, na medida em que os livros são destinados a pais e professores e, estão sempre na direção de pedir tolerância, compreensão e paciência. Os argumentos que justificam este pedido são: a adolescência é passageira, pois se constitui como uma fase do desenvolvimento; a adolescência, como algo necessário no crescimento, é incontrolável; e, por fim, os adultos são seres mais completos e prontos e, portanto, podem controlar a situação.

Pede-se aos adultos que controlem o medo de perder $\circ$ filho e de perder $\circ$ controle, mas não se discute a necessidade do controle (ela é naturalizada) nas relações pais e filhos. Os adultos são incentivados ao controle, à autoridade, à imposição de regras, regras que são do mundo adulto. Mas são também incentivados ao amor, à compreensão, à tolerância, a manterem relações democráticas e a valorizar positivamente $o$ adolescente.

Todas as sugestões são a partir da idéia de que a adolescência é natural. Portanto não há propostas ativas. Recomenda-se apenas a aceitação e a paciência.

A adolescência, da forma apresentada nos textos, não tem gênese social. Nenhuma das suas características é constituída nas relações sociais e na cultura. Assim, ao se pensar a problemática da adolescência não se toma qualquer questão social como referência. $A$ falta de políticas para a juventude em nossa sociedade, a desqualificação e inadequação das atividades escolares para a cultura jovem, o sentimento de apropriação que os pais têm, em nossa sociedade, em relação aos filhos, as contradições vividas, a distância entre o mun- do adulto e mundo jovem, a impossibilidade de autonomia financeira dos jovens que ou não trabalham ou sustentam a família, nenhuma destas questões é tomada como elemento importante para compreender a forma como se apresenta a adolescência em nossa sociedade. As relações familiares são as únicas que aparecem nos textos e são fatores de influência sobre a adolescência, mas não a constituem.

Outra questão importante é que o jovem apresentado nos textos é das camadas de médio ou alto poder aquisitivo. Não há, no entanto, qualquer referência a isto. $O$ adolescente está tomado como universal, quando são evidentes as diferenças entre os grupos das diferentes classes sociais devido a diferentes formas de inserção social. Mas nada disso está apresentado e debatido, pois a adolescência está tomada como universal e natural. Os textos não servem para a compreensão de jovens de outros grupos sociais. Ao contrário, impõe um modelo que, ao não se apresentar no processo do desenvolvimento, leva a consideração de anormalidades e patologias, ao invés de apenas diferenças decorrentes das diferentes inserções na sociedade.

As relações com os adultos são tomadas como conflituosas. Os adolescentes são responsabilizados pelas tensões. Utilizam-se termos como luta para fazer referência a estas relações. Com isto, deixa-se de incentivar relações de parceria social entre pais e fiIhos. Os pais recebem milhares de orientações que devem seguir para aliviar as tensões na família. Cabe a eles salvar as relações. Ficam sobrecarregados de responsabilidade, quando poderiam ver seus filhos adolescentes como parceiros, que como qualquer pessoa, inclusive os próprios pais, têm, em cada momento da vida, projetos, necessidades e possibilidades que são delineadas pela cultura.

Nossa cultura valoriza 0 adulto produtivo. Desvaloriza todas as outras fases da vida: a infância, a velhice e a adolescência, tomadas como fases improdutivas para a sociedade, por isso desvalorizadas. A visão naturalizadora reforça estes valores, ao tomar o desenvolvimento como referência.

A Psicologia não deve manter-se divulgando e reforçando estas visões, pois não contribui para a construção de políticas sociais adequadas para a juventu- 
de; não ajuda a construir projetos educacionais adequados para manter os jovens na escola e a inserir os jovens nos grupos e nas instituições que têm como vocação o debate sobre a juventude. Enfim, a visão naturalizante da adolescência é mais do que uma visão que acoberta as determinações sociais; é uma visão que impede a construção de uma política social adequada para que os jovens possam se inserir na sociedade como parceiros sociais fortes, criativos, cheios de projetos de futuro.

A concepção de adolescência, apresentada nos livros estudados, é uma concepção liberal, fruto do pensamento moderno. No período de ascensão da burguesia, como classe dominante, e do desenvolvimento das forças produtivas do capitalismo, vamos assistir à demanda por um novo tipo de conhecimento. Era preciso ultrapassar o conhecimento estático, submetido à fé e aos dogmas da lgreja. A ciência moderna vem atender a essa necessidade: desmistificar a natureza, valorizar a racionalidade do homem, entendê-lo como um ser que, ao mesmo tempo que faz parte da natureza, possui uma autonomia em relação a ela que permite, dadas as condições favoráveis, o desenvolvimento pleno de capacidades que estão, no homem, em potencial. O sujeito é visto como independente, livre, racional e natural. $O$ homem é visto como sujeito a leis naturais e é, ao mesmo tempo, autônomo, capaz de usar a razão soberana. A realidade também é natural e independente e deve ser conhecida a partir de sua natureza intrínseca sem a presença do homem, uma realidade que tem seu próprio funcionamento. Dicotomiza-se sujeito e objeto; subjetividade e objetividade. “...A separação entre objetividade e subjetividade leva a uma naturalização dos aspectos subjetivos como dos aspectos objetivos, que, em última instância, faz com que esses aspectos pareçam independer uns dos outros. A partir do momento em que são tomados como independentes, passam a serem vistos como autônomos, com movimento próprio e natural..." (Gonçalves, 200 I, p. 47).

É exatamente esse movimento no pensamento moderno que produz a concepção de adolescência que acabamos de estudar. Uma visão da adolescência como natural, independente da realidade material. As observações levam a postular características, deste período do desenvolvimento, como expressões da natureza humana. A realidade social é vista como independente do homem; como algo que interage com o desenvolvimento potencial do homem, podendo contribuir e facilitar esse desenvolvimento, ou impedir e dificultar.

As práticas decorrentes desta visão são remediativas, curativas e terapêuticas, pois, ao postularem um desenvolvimento natural do homem, se propõem a observar seu trajeto, cuidando para que siga o que está previsto pela natureza. Caso se desencaminhe do previsto, lá estará o profissional para intervir e para adaptar. As técnicas de trabalho e os instrumentos utilizados pelos profissionais não são vistos como intervenções ativas que interferem na constituição da adolescência; são técnicas que reforçam a imagem de um ser em conflito e de um ser imaturo e inacabado. São técnicas que se traduzem em explicações da adolescência como uma fase "quase patológica". São técnicas que supõem a possibilidade de, ao se tornar adulto, se está pronto e acabado no desenvolvimento, trazendo para a adolescência uma enorme responsabilidade nas escolhas, nas ações, nas idéias, pois passado este período se estará adulto e as oportunidades de mudanças serão poucas.

As práticas profissionais ficam pensadas como intervenções que "ajudam no amadurecimento", ou seja, que adaptam ao que está estabelecido. São decorrentes desta visão, as produções como as que estudamos, que apresentam as características da adolescência de forma naturalizada, como crise de um desenvolvimento que tem a infância de um lado e o mundo adulto do outro; orientam pais e professores no sentido da tolerância, pois a crise é passageira; que universalizam e igualam todos os jovens, estejam eles onde estiverem, inseridos em qualquer cultura e sociedade. Não contribuem em nada para desvendar as relações sociais e formas de vida como relacionadas à gênese das características da adolescência, deixando, portanto, de apontar qualquer sugestão ou contribuição para a construção de políticas sociais para a juventude. Restringe-se à tolerância.

Em síntese, nosso trabalho, ao buscar compreender a concepção de adolescência presente em nossa sociedade, enfatizou esta concepção naturalizante 
como aspecto que limita e restringe as práticas dos psicólogos a atividades terapêuticas de intervenção em quadros "patologicamente normais" ou "naturalmente patológicos".

Os psicólogos estão, a nosso ver, perdendo a possibilidade de contribuir na construção de políticas públicas para a juventude que, entendendo a adolescência como um período do desenvolvimento com suas características constituídas nas relações sociais e nas formas de produção da sobrevivência, possam contribuir para a ressignificação, pelo adulto, deste período e sugerir novas formas de relacionamento que tenham no jovem um parceiro social. Além disso, os psicólogos devem contribuir com seus saberes para que a adolescência seja vista como de responsabilidade de todos. O que nossos jovens estão fazendo, como estão se comportando deve ser compreendido como fruto das relações sociais, das condições de vida, dos valores sociais presentes na cultura, portanto, como responsabilidade de todos que fazem parte de um conjunto social. Pais, professores, profissionais e adultos em geral devem ser alertados para a responsabilidade que possuem na formação e na construção social de nossa juventude. Não se deve pedir a eles apenas tolerância.

\section{Referências}

Aberastury, A., \& Knobel, M. (1989). Adolescência normal. Porto Alegre: Artmed.

Aguiar, W. M. J., Bock A. M. B., \& Ozella S. (200I). A Orientação Profissional com Adolescentes: um exemplo de prática na abordagem sócio-histórica. Em A. M. B. Bock, M. G. M. Gonçalves \& O. Furtado (Orgs.) Psicologia Sócio-Histórica: uma perspectiva crítica em psicologia (pp. 163-178). São Paulo: Cortez.

Bajoit, G. e Franssen, A.( 1997). O trabalho, busca de sentido. Revista Brasileira de Educação-ANPED, 5 e 6,76-95.

Becker, D. (1989). O que é a adolescência. São Paulo: Brasiliense.

Bock, A. M. B. (1998). Discutindo a concepção de adolescência. RE-criação, 3(I), 57-60.
Bock, A. M. B. (200I). Aventuras do Barão de Munchhausen na Psicologia. São Paulo: EDUC e Cortez Ed..

Calligaris, C. (2000). A adolescência. Coleção Folha Explica. São Paulo: PUBLIFOLHA.

Clímaco, A. A. S. (I99I). Repensando as concepções de adolescência. Tese de doutorado, Pontifícia Universidade Católica de São Paulo, São Paulo.

Domingues, C.M.A.S.; e Alvarenga, A.T. (199I). Identidade e sexualidade no discurso adolescente, Revista Brasileira de Crescimento e Desenvolvimento humano, 7(2), 32-68.

Duarte, N. (1993). A Individualidade Para-si: contribuições a uma teoria histórico-social da formação do indivíduo. Campinas: Autores Associados.

Erickson, E. (1976). Identidade, juventude e crise. Rio de Janeiro: Zahar.

Gonçalves, M. G. M. (200I). A Psicologia como ciência do sujeito e da subjetividade: a historicidade como noção básica. Em A. M. B. Bock, O. Furtado \& M. G. M. Gonçalves (Orgs.), Psicologia Sócio-Histórica: uma leitura crítica na Psicologia (pp. 37-52). São Paulo: Cortez.

Knobel, M.( 1989). A Síndrome da adolescência normal em A.Aberastury \& M. Knobel Adolescência Normal. (pp.24-62). Porto Alegre: Artes Médicas.

Leontiev, A. (1978). O Desenvolvimento do psiquismo. Lisboa: Horizontes Universitários.

Levi, G., \& Schmitt, J. C. (1996). História dos Jovens. (Vol. I). São Paulo: Companhia das Letras.

Levinsky, D. (1995). Adolescência: reflexões psicanalíticas. Porto Alegre: Artes Médicas.

Melucci, A. (1997). Juventude, tempos e movimentos sociais. Revista Brasileira de Educação - ANPED 5 e 6, 05-I4.

Outeiral, J. O. (1994). Adolescer: Estudos sobre adolescência. Porto Alegre: Artes Médicas.

Peralva (1997). O jovem como modelo cultural. Revista Brasileira de Educação - ANPED 5 e 6, I5-24.

Santos, B. R. (1996). Emergência da concepção moderna de infância e adolescência: mapeamento, documentação e reflexão sobre as principais teorias. Dissertação de mestrado, Pontifícia Universidade Católica de São Paulo, São Paulo.

Tiba, I. (1985). Puberdade e Adolescência: desenvolvimento biopsicossocial. São Paulo: Ágora. 
Tiba, I. (1996). Disciplina: limite na medida certa. São Paulo: Gente.

Waldman, L. ( 1 997). E Agora? Tenho um filho adolescente. São Paulo: Mercuryo.
Zagury, T. (1996). O adolescente por ele mesmo: orientação para pais e educadores. Rio de Janeiro: Record.

Zagury, T. (200 I ). Limites sem trauma. ( $12^{\mathrm{a}}$ ed.). Rio de Janeiro: Record.

Recebido em: 31/01/2007

Revisado em: 28/05/2007

Aprovado em: 12/06/2007

Sobre a autora:

Ana Mercês Bahia Bock (anabock@terra.com.br) é professor titular da Pontifícia Universidade Católica de São Paulo, Membro de corpo editorial da Revista Mexicana de Orientacion Educativa e Membro de corpo editorial da Alternativas em Psicologia. 